\title{
Global versus local processing in haptic perception of form
}

\author{
MORTON A. HELLER and SONYA CLYBURN \\ Winston-Salem State University, Winston-Salem, North Carolina
}

\begin{abstract}
Preliminary experiments on a "tactile analog" of Navon's (1977) global/local patternidentification task are reported. Sighted, early-blind, and late-blind subjects were exposed to large shapes comprised of different, smaller geometric forms, and were asked to "name the shape." In addition, groups of early- and late-blind subjects attempted identification of conflict braille stimuli, with large braille patterns made up of smaller, standard braille. The pattern of responses was neither totally local nor global for geometric-form information. Braille, however, was size specific, with most early-blind subjects responding locally. Visual and haptic experience altered the pattern of responses for both braille and geometric forms.
\end{abstract}

The present experiments bear on the issue of whether touch is best suited for the detection of small, distinctive, local features of stimuli or for a global impression of form. In vision, there is some evidence that subjects first process the whole and then notice the parts that comprise it (Navon, 1977). Researchers have proposed that the left cerebral hemisphere is specialized for analytic processing of details, and the right hemisphere is specialized for global analysis (Van Kleeck, 1989). However, many researchers have assumed, after Revesz (1950), that touch operates rather differently. Thus, according to Revesz, the apprehension of a whole is a laborious process that follows the perception of parts (p. 84; see also Heller, 1991). This has led researchers to the belief that in haptic perception, impressions of wholes are slowly constructed via an intellectual process that is memory dependent. If touch functions in a manner that is similar to vision, one would expect that the wholes would be noticed. However, if haptic perception is really a process of slowly building up an impression of form by combining parts, one might expect subjects to identify small tangible letters when given a conflict (see Navon, 1977).

The present experiments tied reliance on proprioception to perception of the global form, but this also reflects the demands of reality-namely, large forms typically require scanning movements and place demands on proprioception. One can't help but wonder if proprioception or cutaneous input would be dominant, given a conflict between the two sources of input. It is difficult to provide a "fair" discrepancy between input from the skin and

Send reprint requests to M. A. Heller, Department of Psychology, Winston-Salem State University, Winston-Salem, NC 27110. Preparation of this report and some of the research were supported by NIH MBRS Grant 2 SO6 RR-08040. Faith Heller provided helpful comments on an earlier version of this manuscript. We are grateful to Emerson Foulke for the loan of the special slate that was used to prepare the forms for the experiment, and to Carl Perry for aid in the preparation of the stimuli and the figures. proprioception, because they normally covary in haptics. Nonetheless, the experiments provided a conflict between proprioception and cutaneous input. Blind subjects touched large braille letters made of different, smaller configurations (Navon, 1977) (see Figure 1). Judgments of the identity of the larger configurations were based largely on proprioceptive information, whereas the identification of the small stimuli maximized the use of cutaneous input. Of course, proprioceptive input was not ruled out as the subjects examined the small shapes. Although it would have been possible to eliminate proprioception and tracing movements with the use of passive touch, this "cutaneous"' task would have drastically lowered performance (see Appelle, 1991; Heller, 1986).

\section{METHOD}

\section{Subjects}

There were 9 sighted subjects, recruited from an undergraduate campus. The 9 early-blind subjects ( 3 male, 6 female) and 9 late-blind subjects ( 7 male, 2 female) were recruited at Industries of the Blind workshops in Winston-Salem and Greensboro, NC. Sixteen of the blind subjects ( 8 early blind and 8 late blind) identified themselves as braille readers, and many of them had served previously in research by the author (see Heller, 1992). The blind subjects participated in both experiments, but started with the braille stimuli.

\section{Stimuli and Apparatus}

The braille stimuli consisted of large embossed characters made up of standard-size braille. The 10 stimuli $(2 \mathrm{~cm}$ high) are shown in Figure 1. The large geometric forms were embossed with a special slate and stylus (see Heller, 1989) that produced dots within a $6 \times 6$ matrix. The dots were embossed on plastic braille cards, with the $7.5-\mathrm{cm}$ circle composed of 1-cm-high squares (see Figure 2); the 6-cm square was made up of 1 -cm-high circles.

\section{Procedure}

For the sighted subjects, vision of the stimuli was prohibited, as they reached through a cloth-covered opening in the base of a large vertical board. All the subjects were asked to use the preferred hand, as measured by writing preference. Each subject was told to extend his/her preferred hand parallel to the table surface with the palm down. A card was placed beneath each subject's hand, and the instructions were to vocally "name the letter or pattern" that was touched (as appropriate). 


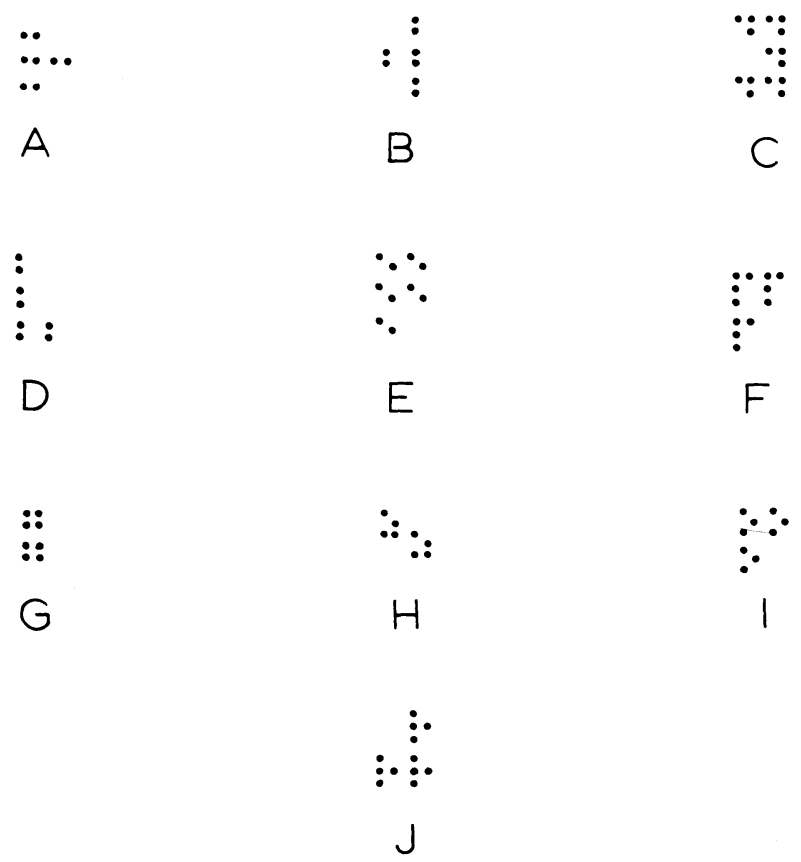

Figure 1. Large braille patterns made up of smaller, standard braille. (A) A large "R" made up of small "c"s. (B) $A$ "W" of small "b"s. (C) A "Y" of small “d"s. (D) A "V" of "b"s. (E) A "Q" of "e"s. (F) An "F" of "p"s. (G) A "B" of "g"s. (H) An "E" of " $z$ "s. (I) An "F" of "O"s. (J) A “J" of "r"s.

The subjects were told to place their hands flat on the surface before making a response. They were told that they could then feel the patterns in any way they wished, and that there were no time limits. The subjects were not timed, as in Navon's (1977) study, because it was thought that timing would have promoted rapid responses, and would discourage them from engaging in naturalistic search behaviors. More significantly, pilot work had indicated that timing prompted large error rates given conflict stimuli. Of course, the lack of timing data suggests caution in drawing conclusions about local or global precedence.

After placing their hands flat on the stimulus card, the subjects then initiated scanning or tracing with the preferred index finger. ${ }^{1}$ The blind subjects were not told the names of the component braille characters, nor were they given feedback.

\section{Results and Discussion}

Table 1 shows the frequency of correct global and local responses for sighted controls, as well as for the earlyblind and late-blind subjects. Haptic responses to geometric shapes were neither totally global nor local. The sighted subjects showed a different pattern of responses than the blind volunteers. A Fisher exact probability test on the data for the "circle of squares" showed a significant difference between the sighted and late-blind subjects $(p<.05)$ in their tendency to make local or global responses. The sighted subjects were far less likely to make local responses than the late blind, indicating the influence of haptic experience. For the geometric forms in general, the sighted subjects tended to notice both the local and global forms; they almost always correctly named "the square of circles." The blind subjects, how- ever, were less likely to notice both the larger and smaller shapes. The late-blind subjects seemed more likely to notice local features and ignore the larger pattern, but an intermediate pattern of responses was obtained for the early blind; these subjects more frequently identified the larger patterns. It was interesting that a couple of sighted controls were unaware that there were small geometric shapes, and expressed surprise when shown the stimuli after the experiment.

A very different pattern of responses was obtained for the blind subjects and braille, indicating the importance of tactile experience (see Table 2). The majority of the blind subjects, especially the congenitally blind volunteers, treated braille as size specific and responded with the smaller patterns. Seven of the 8 congenitally blind subjects showed only local responses, showing a reliance on cutaneous input. A typical answer was that there were two or more smaller braille characters. Thus, " $G$ " in Figure 1 illustrates a large braille " $b$ " made up of two " $g$ "'s. One late-blind subject "thought aloud" and wondered if there could be a larger braille pattern. He quickly answered his question and said that "that is impossible ... that [the larger patterns] could not be braille." All of the global responses in the early-blind group were provided by 1 subject, and that person had had some vision during the first year of her life. Unlike visual print, braille is not normally encountered in different sizes. Most blind people read standard braille, which is $6 \mathrm{~mm}$ high. Jumbo braille ( $8 \mathrm{~mm}$ high) is designed for diabetic individuals with neuropathy.
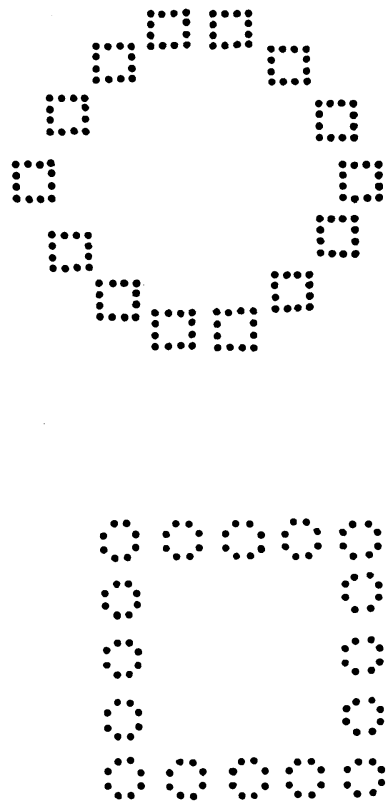

Figure 2. The stimuli in the local/global shape task: The "circle of squares" and the "square of circles." 
Table 1

Number of Correct Responses of Sighted and Blind Subjects for Embossed "Circle of Squares" and "Square of Circles"

\begin{tabular}{lcccc} 
& \multicolumn{4}{c}{ Responses } \\
\cline { 2 - 5 } Subjects & Local & Global & Both & Other \\
\hline Late blind & 10 & 4 & 3 & 1 \\
Early blind & 5 & 9 & 2 & 2 \\
Sighted & 2 & 3 & 11 & 2 \\
\hline
\end{tabular}

Note-The maximum frequency possible was 18 , since there were 9 subjects in each group. Responses identified as "other" consisted of misidentification of both large and small forms.

Table 2

Total Number of Local and Global Responses of Blind Subjects to Large Braille Comprised of Small Braille Characters

\begin{tabular}{lcccc}
\hline & \multicolumn{4}{c}{ Responses } \\
\cline { 2 - 5 } Subjects & Local & Global & Both & Other \\
\hline $\begin{array}{l}\text { Late blind } \\
(n=8)\end{array}$ & 58 & 0 & 20 & 2 \\
$\begin{array}{l}\text { Early blind } \\
(n=8)\end{array}$ & 75 & 3 & 0 & 2 \\
\hline
\end{tabular}

Note-Each of the blind subjects was exposed to 10 braille characters. "Other" responses represent errors. Responses noted as "both" indicate that the subjects correctly identified the large braille pattern as being made up of the smaller, normal braille character.

\section{REFERENCES}

APPELLE, S. (1991). Haptic perception of form: Activity and stimulus attributes. In M. A. Heller \& W. Schiff (Eds.), The psychology of touch (pp. 169-188). Hillsdale, NJ: Erlbaum.

HELler, M. A. (1986). Active and passive tactile braille recognition. Bulletin of the Psychonomic Society, 24, 201-202.

Heller, M. A. (1989). Picture and pattern perception in the sighted and blind: The advantage of the late blind. Perception, 18, 379-389.
Heller, M. A. (1991). Haptic perception in blind people. In M. A. Heller \& W. Schiff (Eds.), The psychology of touch (pp. 239-261). Hillsdale, NJ: Erlbaum.

Heller, M. A. (1992). The effect of orientation on tactual braille recognition: Optimal touching positions. Perception \& Psychophysics, 51, 549-556.

NAvoN, D. (1977). Forest before trees: The precedence of global features in visual perception. Cognitive Psychology, 9, 353-383.

Revesz, G. (1950). The psychology and art of the blind. London: Longmans Green.

VAN KLEECK, M. H. (1989). Hemispheric differences in global versus local processing of hierarchical visual stimuli by normal subjects: New data and a meta-analysis of previous studies. Neuropsychologia, 27, 1165-1178.

\section{NOTE}

1. It was considered possible that the procedure and instructions biased the subjects and generated atypical scanning strategies. For example, one might think that they would normally scan serially, with the tip of one index finger, when first confronted by a pattern. Furthermore, it is possible that the instruction to "name the letter" or "name the shape" altered both scanning and memory search. Consequently, a number of blindfolded, sighted subjects were exposed to the same geometric stimuli of the present experiment, but were told to draw the patterns using a Swedish raised-line drawing kit (see Heller, 1989, 1991). They were given no additional information about the patterns, nor were they told how to touch the stimuli. All the subjects started off by placing their preferred hands flat on the stimuli. In addition, they showed the same pattern of responses as the subjects in the present experimentnamely, they tended to focus on global aspects of form. The drawn forms were not always exact duplicates of the stimuli. Moreover, some subjects described the large circle as more like a hexagon. This suggests that categorical information probably played a role in the reported experiments. When told to draw the patterns, some of the subjects drew large patterns made up of smaller configurations, suggesting that haptic processing need not be totally global or local. However, these individuals all started tactual examination with a scan of the large pattern, and then began the examination of the small, component patterns.

(Manuscript received June 21, 1993.) 